\title{
Fiscalização no mercado de trabalho e informalidade nos municípios brasileiros
}

Auditing and informality on Brazilian labor market

\begin{abstract}
Since the 90s the government has developed a number of enforcement actions in the labor market in Brazil. This work aims to investigate the effects of enforcement of labor regulation on informality in Brazilian municipalities. For this, a database is used with information on establishments inspected by staff of the Department of Labour Inspection (SIT) in 786 municipalities of the country for the period 1996 to 1999. In addition, the methodological approach considers the fact that the choice of firms inspected depend on the mode of operation. The inspection decision depends on geographical factors, such as distance and economic density, and the availability of the number of tax for micro-region of the country. The results obtained following an instrumental variable approach, indicate a negative and significant effect of supervision over the contingent of informal workers in these municipalities.
\end{abstract}

\section{Keywords}

enforcement of labor market; informality; labor regulation.

JEL Codes J46; J68; K31.

\author{
Enlinson Mattos (1) \\ Ricardo Politi (2) \\ Gabriela Fuschini ${ }^{(3)}$ \\ (1) Fundação Getulio Vargas \\ (2) Universidade Federal do ABC \\ (3) Tendencias Consultoria
}

\section{Resumo}

Desde a década de 90 o governo tem desenvolvido diversas ações de fiscalização do mercado de trabalho no Brasil. Este trabalho visa investigar os efeitos da fiscalização sobre a informalidade nos municípios brasileiros. Para isso, é utilizado um banco de dados com informações sobre estabelecimentos fiscalizados pelas equipes da Secretaria de Inspeção do Trabalho (SIT) em 786 municípios do país para o período de 1996 à 1999. Adicionalmente, a abordagem metodológica considera o fato da escolha das firmas fiscalizadas depender do modo de operação dos fiscais. A decisão de fiscalização depende de fatores geográficos, como distância e densidade econômica, além da disponibilidade do número de fiscais por microrregião do país. Os resultados, obtidos por meio de uma abordagem de variável instrumental, apontam para um efeito negativo e significante da fiscalização sobre o contingente de trabalhadores informais nesses municípios.

\section{Palavras-chave}

fiscalização no mercado de trabalho; informalidade; regulação trabalhista.

Códigos JEL J46; J68; K31. 


\section{Introdução}

Uma das principais características do mercado de trabalho no Brasil é o elevado nível de informalidade, problema econômico relevante, pois afeta o bem-estar da sociedade em diversos aspectos. Em primeiro lugar, a informalidade diminui o acesso dos trabalhadores aos benefícios trabalhistas previstos na respectiva legislação, como por exemplo o seguro desemprego. Em segundo lugar, diminui as receitas do governo com as contribuições trabalhistas. De fato, além dos seus impactos na precarização do mercado de trabalho, a informalidade tem despertado debates na literatura econômica devido aos seus efeitos sobre o crescimento da economia (Fugazza; Jacques, 2003) e sobre a competição desleal entre firmas formalizadas e informais (Perry et al., 2007).

Complementar a questão da informalidade é a discussão sobre fiscalização da atividade informal e punição às firmas não cumpridoras da lei. De acordo com a teoria econômica, espera-se que localidades com melhor ambiente institucional apresentem menor proporção de atividades ilegais ou em desacordo com a legislação local (Fugazza; Jacques, 2003). Nesse aspecto, uma discussão relevante é compreender o efeito da fiscalização, e da consequente ameaça de punição (por enforcement na literatura internacional), sobre as firmas que atuam e contratam trabalhadores de maneira informal.

O objetivo deste artigo é investigar o efeito da fiscalização sobre o nível de informalidade no mercado de trabalho nos municípios brasileiros, a fim de verificar a eficiência no combate à informalidade. Para isso, é utilizado um banco de dados do Ministério do Trabalho e do Emprego (MTE) referentes aos estabelecimentos fiscalizados pelas equipes da Secretaria de Inspeção do Trabalho (SIT) nos municípios de diversas microrregiões do país para o período de 1996 à 1999. ${ }^{1}$ Esse período foi definido a partir da disponibilidade de informações referentes ao número de estabelecimentos fiscalizados, número de fiscais por Estados, Gerências e Agências do MTE para os municípios e a possibilidade de identificação dos municípios na PNAD. Em especial, é investigado como o número de estabelecimentos fiscalizados em relação ao total de firmas de 786 municípios brasileiros presentes na amostra continuada da PNAD afeta a proporção de trabalhadores informais na localidade.

1 Dados sobre esse período ainda não foram utilizados para investigar a informalidade no Brasil. 
Em termos empíricos, um ponto central da abordagem metodológica é discutir quais são os determinantes da fiscalização nas localidades. Conforme discutido em trabalhos anteriores, a fiscalização no mercado de trabalho no Brasil, assim como na grande maioria dos países, não é um processo aleatório (Almeida; Carneiro, 2012). De fato, a maior ou menor probabilidade de fiscalização deve estar associada a fatores observados, como a presença nas microrregiões de agências ou gerências do MTE, distância das localidades investigadas da capital estadual (e a respectiva sede da Superintendência do MTE no Estado); como também está associada a fatores não observados no banco de dados utilizados nesta pesquisa, como denúncias de trabalho escravo ou trabalho infantil, ou violações da lei trabalhista, ou ainda relacionadas ao ambiente institucional. Para estimar de maneira consistente o efeito da fiscalização sobre a informalidade no mercado de trabalho nos municípios brasileiros, será utilizada a abordagem de variável instrumental.

Os resultados da presente pesquisa indicam que o efeito da fiscalização sobre o percentual de trabalhadores informais nos municípios é significante e negativo, ou seja, quanto maior o percentual de estabelecimentos fiscalizados dentro do município, menor a taxa de informalidade. Os resultados obtidos por meio de uma abordagem de variáveis instrumentais sugerem que para cada $1 \%$ de aumento de estabelecimentos fiscalizados por 1000 firmas no município, há um decréscimo de 0,10\% na parcela de trabalhadores que atuam no setor informal (conta própria ou informais nas empresas). Esses resultados estão em sintonia com os resultados obtidos em pesquisa anterior (Almeida; Carneiro, 2012) e parecem consistentes, considerando-se os resultados de teste do nível de significância das variáveis escolhidas como instrumentos nas regressões e de teste de potencial endogeneidade (simultaneidade).

Antes de apresentar os resultados da abordagem econométrica, este artigo traz uma breve discussão sobre legislação trabalhista e mercado de trabalho no Brasil na seção 2. A atuação do SIT nas microrregiões do país é discutida na seção 3 . Na seção seguinte é discutida a abordagem econométrica e é apresentado em detalhe o banco de dados utilizado neste trabalho. A Seção 5 comenta os principais resultados da investigação empírica. Por fim, a seção 6 conclui o trabalho. 


\section{Ambiente institucional e referencial analítico}

De acordo com levantamento feito pelo grupo internacional Tax Justice Network, ${ }^{2}$ o Brasil é o segundo país no mundo em termos de valores de impostos perdidos devido à economia informal, atrás apenas dos Estados Unidos da América (EUA) em termos absolutos. De acordo com essa entidade, estima-se que o tamanho do setor informal no Brasil é de cerca de $39 \%$ do PIB, e que o valor total de impostos perdidos devido à informalidade seja de USD 280 bilhões. No contexto da informalidade, a soma do grupo de trabalhadores que se autodeclara sem carteira assinada ou, ainda, que trabalha por conta própria atinge cerca de $40 \%$ da população economicamente ativa no Brasil (Ulyssea; Paes de Barros, 2010), fazendo da informalidade um problema econômico grave no país.

Por sua vez, um fenômeno importante no mercado de trabalho no Brasil desde 2000 tem sido o aumento da formalidade nas relações trabalhistas (Corseuil et al., 2012). De acordo com dados da STI/MTE, entre os anos de 2001 e 2007, a participação dos trabalhadores com carteira de trabalho assinada aumentou $36 \%$, em contrapartida, a participação dos trabalhadores sem carteira assinada aumentou apenas $13 \%$. Por conta dessa tendência, a participação da informalidade, caiu de $38,5 \%$ para $34,2 \%$ entre os trabalhadores. Considerando-se também os trabalhadores por conta própria, essa participação caiu de $58,4 \%$ para $53,4 \%$.

Para diversos autores, além do aumento da atividade econômica, sobretudo a partir de 2003, a queda da informalidade também está associada a alterações no modo de operação da inspeção de trabalho no Brasil. ${ }^{3}$ Berg (2010), por exemplo, destaca uma mudança na abordagem na inspeção do trabalho no Brasil. Foi criada uma estrutura de incentivos, como a introdução, nos anos 90 , de um sistema de bônus pelo qual uma porcentagem substancial dos salários dos inspetores estava vinculada a metas de desempenho individual, bem como ao desempenho total da inspeção do trabalho. O novo sistema explicitou por objetivo formalizar trabalhadores, a cobrança das contribuições patronais para o fundo de FGTS, bem como ampliar o número de trabalhadores cobertos pela inspeção. Essa nova abordagem teve um impacto importante sobre o sucesso

3 Vide Corseuil et al. (2012) para uma discussão mais ampla. 
da inspeção do trabalho no país, bem como para o sucesso do combate à informalidade.

Outro trabalho que discute o modo de operação da inspeção no mercado de trabalho sobre a informalidade é Pires (2008). O autor procura distinguir por meio de uma análise comparativa os efeitos entre duas estratégias de inspeção do trabalho diferentes: ações coercitivas (deterrence model) versus ações pedagógicas (compliance model). Inspeções de acordo com políticas de detenção são baseadas na ideia de penalização, por meio do aumento dos custos das firmas não estarem de acordo com a legislação vigente, as firmas seriam incentivadas a se formalizarem. Por outro lado, o modelo de ações pedagógicas surgiu a partir da crítica dos impactos negativos do modelo de penalização. Ao invés de aplicar sanções e multas, inspetores deveriam tentar entender o "espírito da lei" e adaptar a legislação para cada tipo de firma, sempre priorizando a persuasão e o aconselhamento ao invés da punição. Seu argumento principal é que uma estratégia de fiscalização que combina ambos os modelos possibilita a criação de soluções locais inovadoras.

O resultado de seu estudo de campo aponta que as duas abordagens utilizadas individualmente são limitadas, ou melhor, insuficientes para promover o cumprimento das normas trabalhistas por parte das empresas. $\mathrm{Na}$ realidade, um nível sustentável de cumprimento da lei só é alcançado por meio da combinação dos dois tipos de modelo, isto é, uma combinação entre sanções, multas, conselhos e assistência, resultado de um conjunto das estratégias coercivas e pedagógicas.

Outro trabalho recente utiliza pesquisa de campo para investigar os efeitos de diferentes ações sobre a formalização das firmas que se enquadram no SIMPLES nacional. Andrade et al. (2014), utilizando dados de 2009 do Sebrae (Serviço Brasileiro de Apoio às Micro e Pequenas Empresas), conduzem um experimento em que firmas informais no município de Belo Horizonte são divididas aleatoriamente em quatro grupos com ações diferentes e um grupo de controle (sem ação ou sem tratamento). No primeiro grupo, no qual a ideia é testar o impacto da informação sobre o comportamento das firmas, elas são informadas sobre os procedimentos burocráticos para formalização. No segundo caso, as firmas recebem essa informação e uma isenção nas taxas necessárias para a formalização. No terceiro caso, as firmas recebem a visita de fiscais, e no quarto caso é acompanhado o efeito da fiscalização sobre firmas vizinhas. De maneira 
interessante, os autores identificaram que a única ação efetiva para aumentar os níveis de formalização das firmas foi o aumento da fiscalização. Segundo os autores, a probabilidade de formalização aumentou entre 21 e 27 pontos percentuais.

Em uma pesquisa mais semelhante a esta, Almeida e Carneiro (2012) investigam o impacto das inspeções fiscais na informalidade do mercado de trabalho no Brasil. As variáveis utilizadas como medidas da inspeção do trabalho são a média do número de inspeções por firma nos municípios e a proporção de trabalhadores alcançados pelos fiscais. Segundo os autores, em locais com inspeções frequentes, os trabalhadores pagam pelos benefícios obrigatórios recebendo salários mais baixos. Como existe rigidez salarial, alguns empregos no setor formal tornam-se atraentes para alguns trabalhadores informais, induzindo-os à formalização. Usando dados longitudinais para os municípios e para a fiscalização do trabalho do ano 2000, os autores encontram que em resposta a um aumento nas inspeções do trabalho, observou-se aumento do emprego formal, diminuição do emprego informal, aumento do desemprego, redução dos salários no topo da distribuição de renda formal, e aumento em salários informais. Essencialmente, o movimento do setor informal para o setor formal se deu entre os trabalhadores autônomos.

$\mathrm{Na}$ discussão sobre evasão fiscal, dois aspectos relevantes costumam ser abordados na literatura econômica. Primeiro, que o aumento das obrigações fiscais, usualmente via aumento de impostos ou aumento de alíquotas, está associado ao aumento da informalidade. $O$ segundo aspecto está associado à ideia de que a maior probabilidade de fiscalização ou o aumento da punição para a firma que seja descoberta infringindo a lei tenderia a diminuir a ocorrência de informalidade na economia (Fugazza; Jacques, 2003).

Desse modo, por um lado, o aumento de custo da mão de obra no setor formal decorrente do maior acesso a benefícios trabalhistas tenderia a diminuir o número de vagas disponíveis no setor formal e poderia incentivar a migração de vagas para o setor informal da economia. Por outro lado, quanto mais os benefícios trabalhistas (como salário, FGTS, férias remuneradas) estão associados a empregos no setor formal, mais os trabalhadores buscariam fazer parte desse setor (Ahn; De La Rica, 1997). De fato, esse efeito sobre a procura de empregos no setor formal seria maior à medida que os trabalhadores valorizassem mais esses benefícios (Almeida; Carnei- 
ro, 2012). Na próxima seção, é discutida a legislação trabalhista e o modo de operação dos fiscais de trabalho no país.

\section{Legislação e fiscalização do trabalho no Brasil ${ }^{4}$}

No Brasil, a Constituição Federal lançada em 1988 ampliou os direitos e a proteção dos trabalhadores em diversos âmbitos. Tais avanços podem ser brevemente resumidos pelos seguintes pontos: aumento do custo de demissão sem justa causa de $10 \%$ para $40 \%$ de multa sobre o Fundo de Garantia (FGTS), redução da jornada máxima de trabalho semanal de 48 horas para 44 horas, aumento da remuneração da hora extra de 1,2\% para $1,5 \%$ do salário normal, aumento dos pagamentos de férias para $1 / 3$ do salário mensal, instauração do banco de horas, tornando as horas de trabalho mais flexíveis, aumento da licença maternidade de 90 dias para 120 dias, e instauração de 5 dias de licença paternidade. ${ }^{5}$

De acordo com a Constituição Federal de 1988, no caso das relações trabalhistas patrão/empregado, para que os empregados estejam regularizados no setor formal da economia é necessário que o patrão cumpra todos os direitos previstos na legislação trabalhista da Consolidação das Leis do Trabalho (CLT), que são: registro do trabalhador na carteira (carteira de trabalho assinada), cumprimento da jornada de trabalho e do período de descanso, pagamento de férias remuneradas e de $13^{\circ}$ salário, entre outros direitos citados acima.

Já no caso do trabalhador autônomo, para que se opere na formalidade

E necessário registro na Junta Comercial e, em função da natureza das atividades constantes do objeto social, inscrições em outros órgãos, como Receita Federal (CNPJ), Secretaria de Fazenda do Estado (inscrição estadual e ICMS) e Prefeitura Municipal (concessão do alvará de funcionamento conforme a atividade pode requerer autorizações de órgãos responsáveis pela saúde, segurança pública, meio ambiente e outros). (Portal do Empreendedor, website, 2015).

Também é necessária a inscrição no FGTS (Caixa Econômica Federal) e a inscrição nos conselhos de classe, quando for o caso (CREA, CRM, CRC etc.).

4 Essa discussão está baseada principalmente na Portaria № 153 de 2009 que aprova o Regimento Interno das Superintendências Regionais do Trabalho e Emprego e em Almeida e Carneiro (2012), pp. 68-69.

5 Vide Barros e Corseiul (2004) para uma discussão. 
Qualquer empregado que não esteja contratado de acordo com as leis da CLT e qualquer autônomo que não cumpra os registros previstos acima compõe o setor informal brasileiro. Tais trabalhadores não possuem seguridade social sendo, dessa maneira, mais desprotegidos, pois, em caso de doença, invalidez, maternidade ou desemprego, não possuem nenhuma proteção nem benefício por não estarem regularizados. Normalmente, os trabalhadores informais são envolvidos com evasão fiscal, uma vez que não declaram sua renda e não pagam os devidos impostos sobre ela.

Dentro do Ministério do Trabalho, a Secretaria de Inspeção do Trabalho (SIT) é o órgão responsável por fazer cumprir a regulamentação do trabalho no Brasil. Regulamentada pela Lei 10.593 de 2002, a SIT vem realizando diversos Planos Plurianuais para combater o emprego informal no país que, segundo dados dessa Secretaria, atingiu 16 milhões de trabalhadores em 2015. O principal foco da fiscalização são os registros em carteira de Trabalho e Previdência Social (CTPS) e recolhimento do FGTS.

Dada a dimensão do país, a execução é descentralizada primeiro em nível estadual e, em seguida, em nível local por sub-região. Cada Estado possui uma Superintendência Regional do Trabalho e do Emprego (SRTE), conhecidas até 2007 como Delegacias Regionais do Trabalho. A fiscalização é realizada no âmbito das Gerências Regionais do Trabalho e do Emprego (GRTE) e das Agências Regionais (AR) de acordo com as diretrizes estabelecidas pela SIT. ${ }^{6}$ As Agências e as Gerências estão localizadas em diferentes cidades, e suas áreas de abrangência incluem geralmente mais de um município, focando a microrregião do país.

Em cada Estado, a SRTE está sempre localizada na capital do Estado e o número de Gerências e Agências nos Estados é uma função do tamanho e da importância econômica de cada região. Por exemplo, em 2014, no Estado de São Paulo existiam 26 Agências e 13 Gerências, enquanto que em Estados menos populosos, como Acre ou Tocantins, só apresentavam uma Agência. Vale ressaltar que um mesmo município não apresenta Agência e Gerência do MTE.

As auditorias realizadas pelo auditor fiscal podem acontecer de duas maneiras. O Ministério do Trabalho, por meio da SIT, em parceria com 6 As Delegacias Regionais do Trabalho foram criadas pelo Decreto-Lei $n^{\circ} 2.168$ do ano de 1940. O Decreto $n^{\circ} 6.341$ do ano de 2008, alterou a nomenclatura das Delegacias Regionais do Trabalho para Superintendências Regionais do Trabalho e Emprego, das Subdelegacias do Trabalho para Gerências Regionais do Trabalho e Emprego e das Agências de Atendimento para Agências Regionais. A nomenclatura atual é utilizada no decorrer do trabalho. 
os Superintendentes de cada Estado, realiza um planejamento no início de cada ano letivo, com metas e prazos a serem cumpridos durante o ano por SRTE. Tal planejamento é chamado de Plano Plurianual (PPA), e divulga metas específicas de auditoria (número de auditorias mínimas de trabaIho escravo ou trabalho infantil, por exemplo, ou um valor de arrecadação mínimo de FGTS). Dessa forma, os auditores fiscais trabalham no sentido de cumprir as metas propostas no PPA. Por exemplo, em sintonia com o PPA da época, as ações fiscais passaram de 249.795, no ano de 1999, para 525.253, no ano de 2000.

Paralelamente, a auditoria pode se dar devido à denúncia anônima, que pode vir por parte dos empregados ou de qualquer pessoa que reconhecer uma situação ilegal e resolver denunciar. A principal função do auditor fiscal do trabalho é promover o cumprimento das leis de proteção do trabalho por parte dos empregadores, garantindo assim todos os direitos trabalhistas aos empregados. Quando confrontados com violações do código de trabalho, os inspetores devem notificar imediatamente a empresa. A empresa, em seguida, tem 10 dias para apresentar provas em sua defesa. Após esse período, o processo é reexaminado por um inspetor diferente daquele que emite a multa original, que delibera sobre a sua justiça, e o resultado é relatado para a cabeça da subdelegacia.

Como a fiscalização age com o objetivo que todos os trabalhadores de uma empresa apresentem carteira assinada e sejam devidamente regularizados, tenham todos os benefícios pagos e, principalmente, tenham todos os impostos devidamente pagos, o fiscal do trabalho também atua no sentido de aumentar a arrecadação do governo, não permitindo a existência de trabalhadores informais sem carteira de trabalho e sem o pagamento ao INSS; atuando diretamente no combate à informalidade no mercado de trabalho.

É importante perceber que a localização dos escritórios regionais (Gerências e Agências) seguem essencialmente a divisão de microrregiões do Brasil. De acordo com o banco de dados de fiscalização do MTE utilizado nesta pesquisa, no ano 1999, 255 municípios brasileiros possuíam alguma representação do MTE, sendo que 102 municípios apresentavam ao menos uma Gerência e 153 municípios apresentavam alguma Agência, além das 27 STE. É importante notar que essas 255 representações em municípios estavam distribuídas por 217 microrregiões diferentes do país (cerca de $40 \%$ do total), sendo que 94 microrregiões possuem pelo menos uma Gerência e 96 municípios apresentam pelo menos uma Agência. 


\section{Figura 1 Fiscalização no mercado de trabalho no Brasil de 1996 até 1999}

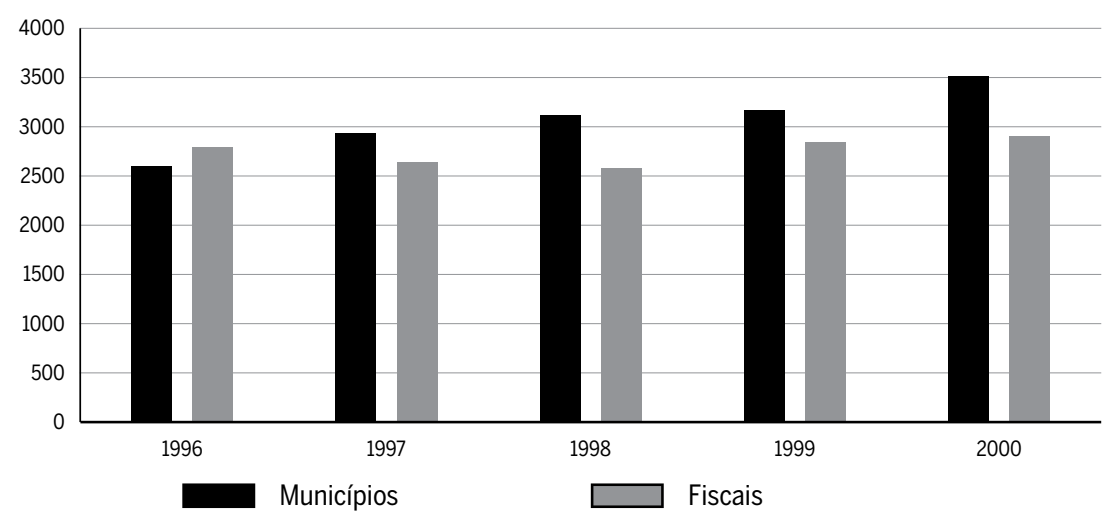

Fonte: SIT. Elaboração dos autores.

Conforme mostra a Figura 1, no período de 1996 à 2000, o número de fiscais ficou relativamente estável, ao redor de 3.000 em todo o país, ${ }^{7}$ mas o número de municípios que tiveram pelo menos um estabelecimento fiscalizado no ano subiu de 2.601 para 3.509. De fato, nesse período de cinco anos, em cerca de $22 \%$ dos municípios não houve nenhuma fiscalização, por outro lado, cerca de $34 \%$ dos municípios foram fiscalizados em todos os anos da amostra. Interessante destacar que das 554 microrregiões do país no ano 1999, apenas 25 microrregiões não receberam nenhuma fiscalização, todas da região Norte e Nordeste. Assim, quando se examina a abrangência da fiscalização, percebe-se que ela atinge uma proporção maior em termos de microrregiões do que em termos de municípios.

Outro aspecto importante do modo de operação da fiscalização, conforme formalizado no Plano Nacional de Combate à Informalidade de 2014, é que a escolha das localidades deve considerar a densidade econômica. ${ }^{8}$ Ou seja, um aspecto importante do modo de operação geográfico da fiscalização no país está relacionado àdivisão dos municípios por microrregião

7 O número de fiscais é um pouco menor do que é divulgado pelo MTE, pois enquanto o MTE considera o número de fiscais em dezembro de cada ano, aqui é considerada a média anual.

8 De acordo com o MTE, "O direcionamento das ações fiscais prioriza regiões e setores econômicos com maior índice de informalidade, por meio do mapeamento da informalidade do Brasil por atividade econômica, município, microrregião e unidade federativa, além da utilização da inteligência fiscal para localização de empresas que mantêm empregados informais." Vide: http://www.brasil.gov.br/economia-e-emprego/2015/10/governo-realiza-acoes-de-combate-a-informalidade. 
e sua densidade econômica. Além dessas características geográficas, conforme destacado em Almeida e Carneiro (2012), a maior parte dos deslocamentos se dá por meio de viagens rodoviárias e depende do número de fiscais por STE, Gerência ou Agência, ou seja, a distância entre o ponto de partida do fiscal e o seu tempo de viagem até os estabelecimentos a serem fiscalizados.

Adicionalmente, é importante enfatizar a tendência da fiscalização de se concentrar sobre as firmas formais em contraposição às firmas informais, onde imagina-se que estariam a maior ocorrência de vagas informais (Almeida; Carneiro, 2012). Portanto, uma grande fração do emprego informal é deixada de fora do alcance dos inspetores. Os fiscais do trabalho não auditam empresas que não possuem sua atividade regulamentada, pois isso está fora de sua jurisdição; isto é, os fiscais do trabalho não possuem autorização para auditá-las. Como a seleção dos estabelecimentos fiscalizados não é aleatória, mas depende do número de fiscais disponíveis no Estado (por meio da STE) e do plano de combate ao desemprego, é importante que o referencial metodológico considere esse potencial problema de viés de seleção. A metodologia usada neste trabalho permite abordar essa peculiaridade da inspeção de trabalho no Brasil e é detalhada na próxima seção. ${ }^{9}$

\section{Referencial metodológico}

\subsection{Dados, definição das variáveis e segmentação}

Os dados referentes à fiscalização foram obtidos junto ao MTE (Ministério do Trabalho e Emprego). Esse banco de dados do MTE, obtido originalmente para este trabalho, contém a contagem das fiscalizações realizadas por todos os Auditores Fiscais do Trabalho por UORG (Unidade Organizacional de Fiscalização) e por Município. O período cedido pelo MTE contém informações mensais de 1996 a 2000. Este tipo de extração tem a vantagem de mostrar efetivamente a ação da Auditoria, não contando os auditores em cargo de chefia, em férias ou licença.

9 Já a fiscalização de empresas informais (do tipo camelôs e ambulantes) é realizada pelos Fiscais Municipais (competência de cada município). Além disso, alguns casos de informalidade, como contrabando ou falsificação, são auditados pela Polícia Federal, por ser competência do governo federal. 
Em relação aos dados municipais, no Brasil, o único banco de dados que contém informações detalhadas é o Censo. Porém, a periodicidade de coleta dessas informações, como é amplamente conhecido, é decenal. Uma alternativa para explorar informações com repetições na dimensão temporal é utilizar os microdados (informações individuais) coletados continuamente para um determinado grupo de municípios pela Pesquisa Nacional por Amostra de Domicílios (PNAD). A PNAD é uma pesquisa domiciliar que ocorre todos os anos em grande parte dos municípios brasileiros. Os domicílios pesquisados mudam todos os anos, e, portanto, a PNAD não compõe um painel de indivíduos. Porém, o conjunto de municípios pesquisados é definido no início de cada década e repetido nos anos seguintes. Nesse caso, o importante para usar esses dados é identificar essas informações segundo os municípios pesquisados. Assim, para o período de 1996 a 1999, a partir das informações disponibilizadas para a PNAD, são calculadas as médias dos dados disponíveis para os 786 municípios da amostra continuada, compondo uma amostra total de 3.144 observações. ${ }^{10}$

Dessa forma, a partir dos microdados da PNAD são geradas médias das informações municipais referentes à renda familiar, escolaridade, proporção de idosos, proporção de crianças, proporção de brancos e proporção de homens. Devido ao componente geográfico do modo de operação dos fiscais, são levantados dados geográficos das localidades como área, distância euclidiana das localidades para a capital Estadual (sede da STE do MTE no Estado), além de dados de população das localidades. Todas essas informações são disponibilizadas pelo IBGE (Instituto Brasileiro de Geografia e Estatística). ${ }^{11}$ Por fim, são levantados dados sobre o número de firmas e funcionários de cada município por meio dos dados do Cadastro Central de Empresas do IBGE, que traz o número de firmas registradas no Cadastro Nacional de Pessoa Jurídica (CNPJ). Com base nessas informações, são geradas as variáveis de controle com informações estaduais e municipais,

10 De fato, o número de municípios total da PNAD continuada é de 808, porém em apenas 786 municípios estão disponíveis todas as variáveis descritas na Tabela 1 e é essa amostra que compõe o painel balanceado utilizado nesta pesquisa. Os microdados dos municípios da amostra continuada da PNAD já foram utilizados por Foguel e Barros (2010) para investigar o efeito de programas de transferências diretas (como o Bolsa Família) na oferta de trabalho nas localidades. Para uma discussão detalhada do uso desses dados e suas eventuais limitações, vide Foguel e Barros (2010) p. 263-264.

11 Vide: http://www.ibge.gov.br/home/geociencias/cartografia/default_territ_area.shtm. 
as variáveis que serão utilizadas como variáveis instrumentais em sintonia com a estratégia econométrica explicada anteriormente e a variável de fiscalização e variável de informalidade dos municípios.

Para definir variável dependente referente à participação de trabalhadores informais, foram considerados os assalariados do setor privado e trabalhadores domésticos que não possuem carteira de trabalho assinada, autônomos e empregadores que não contribuem para a previdência social, trabalhadores não remunerados e trabalhadores que produzem bens para uso próprio que também não contribuem para a previdência social. Já como variável de fiscalização, de forma similar a Almeida e Carneiro (2012), foi considerado o logaritmo do número de inspeções por 1000 estabelecimentos em cada município. Levando em conta que o modo de operação dos fiscais considera a densidade econômica de cada microrregião, foi criada uma variável de fiscalização que considera o logaritmo do número de estabelecimentos fiscalizados por $1000 \mathrm{~km}^{2}$. Essa variável procura explorar o caráter geográfico da fiscalização, considerando-se que com a nova estrutura de incentivos implementada na década de 90 (descrita na seção 2) seja razoável supor que os fiscais procurem aumentar sua produtividade, priorizando a fiscalização de localidades com maior densidade de firmas.

A Tabela 1 traz a estatística descritiva total (média e desvio padrão) das variáveis e também as divide em duas amostras. A primeira amostra contém apenas os municípios que tiveram estabelecimentos fiscalizados todos os anos do período da amostra, enquanto que a segunda amostra contém os municípios que não tiveram nenhum estabelecimento fiscalizado em pelo menos um dos anos do período de análise. A análise das médias por amostra torna evidente que existem diferenças econômicas e demográficas entre os municípios fiscalizados todos os anos e aqueles que não são fiscalizados (ou não foram fiscalizados em todos os anos da amostra). Nessa amostra, comparados com a média geral, os municípios fiscalizados todos os anos tendem a apresentar uma população bem maior, são mais ricos em termos de renda familiar, ficam mais próximos das capitais estaduais e apresentam maior densidade populacional e de firmas. De maneira interessante, também tendem a apresentar menor participação de trabalhadores informais. Essa diferença entre os perfis dos municípios reforça a necessidade de se adotar uma abordagem que produza estimativas que minimizem o problema de viés de seleção. 


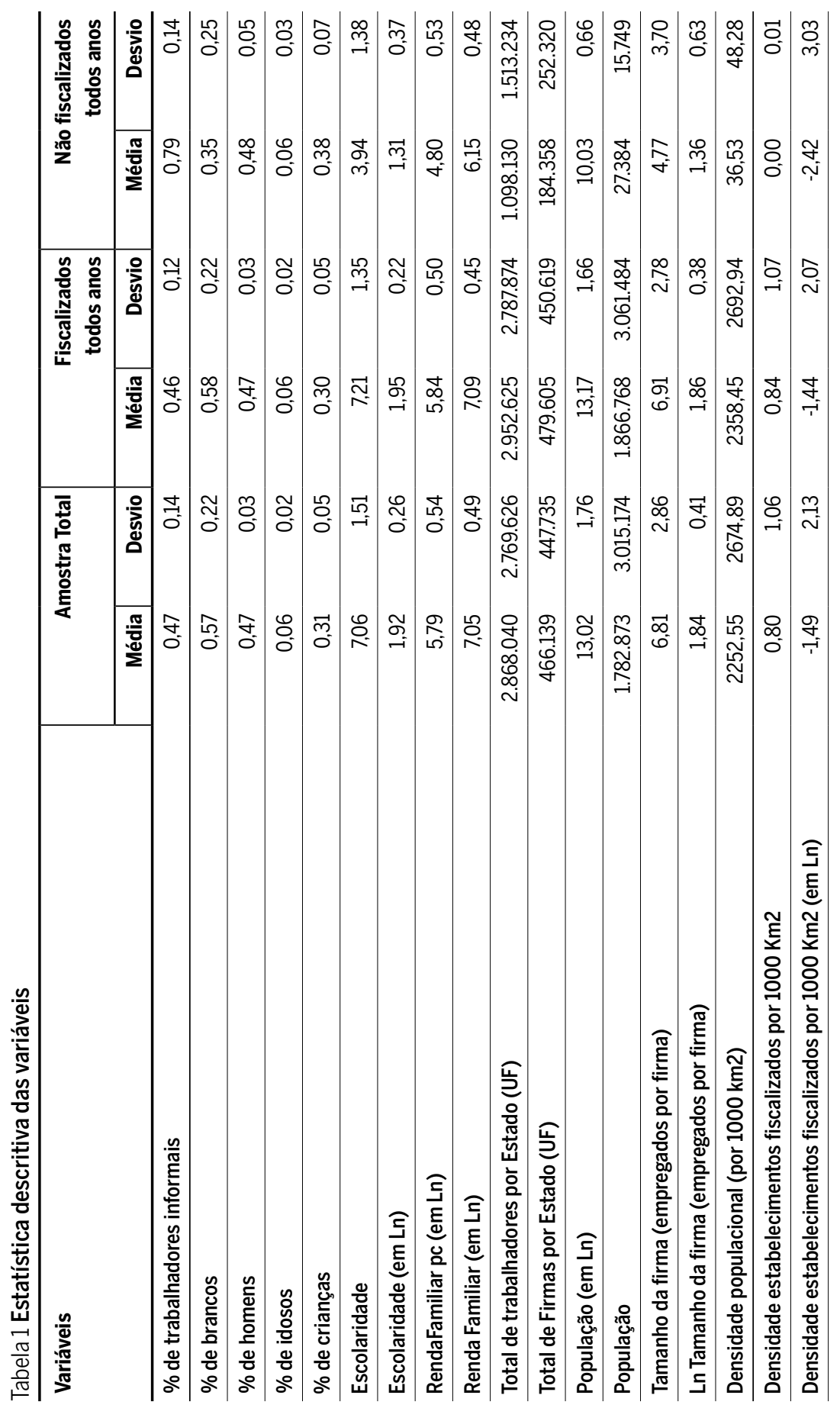




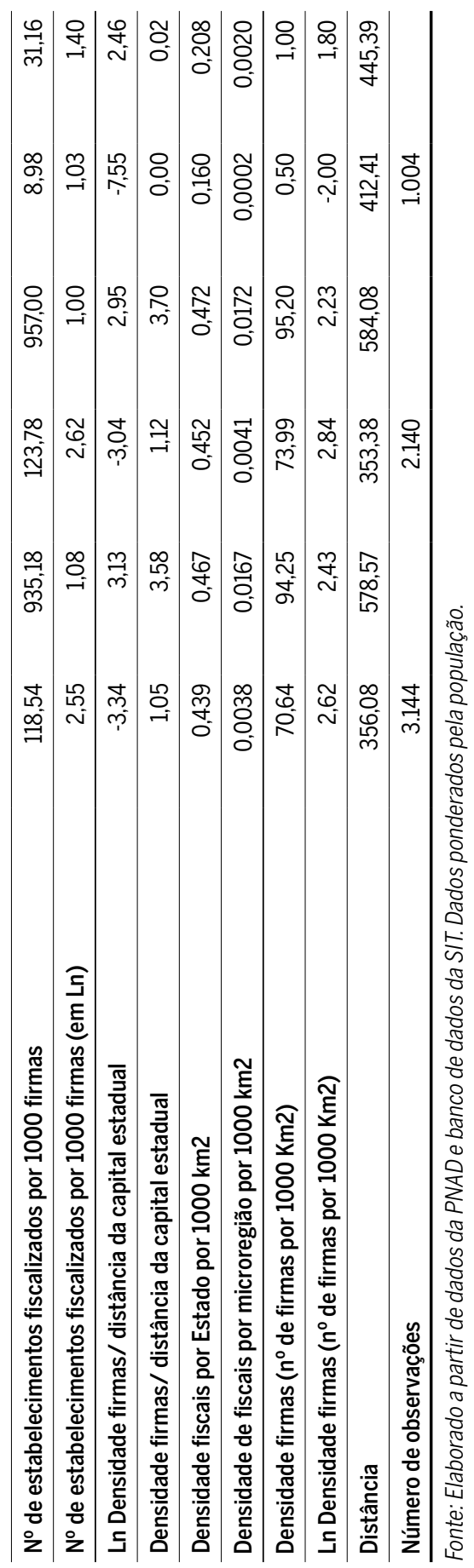




\subsection{Estratégia de identificação}

Conforme discutido na seção 3, a fiscalização do trabalho informal no Brasil se concentra em firmas formais e em regiões onde a atividade econômica é mais relevante. Portanto, um ponto fundamental da estratégia empírica é considerar que o modo de operação da fiscalização produz escolhas não aleatórias. Existem diversas formas de abordar a questão de viés de seleção e produzir estimativas consistentes.

Uma estratégia é tentar identificar alguma característica da localidade que esteja associada à ocorrência da fiscalização e que não esteja associada à alguma outra característica não observada da regressão. Ou, em outras palavras, que não esteja associada ao termo de erro. Essa é a base da abordagem de variável instrumental (IV), segundo a qual a correlação entre a variável de interesse e o efeito da fiscalização sobre a informalidade no mercado de trabalho está associada às variáveis escolhidas como instrumentos, e não de choques comuns observados em todas as localidades (como crescimento da economia) ou ainda a variáveis não observadas, como ambiente institucional e políticas públicas locais.

Nesse contexto, a forma funcional (1) segue:

$$
Y_{i t}=\propto+\beta \hat{F}(Z)_{i t}+\varphi X_{i t}+\text { Micro }_{m}+T_{t}+\mu_{i t}
$$

em que $Y$ traz a informalidade no município $i$ no ano $t$. Já a variável $\hat{F}$ representa a variável de interesse de fiscalização que é instrumentalizada (Z). O vetor $X$ representa outras variáveis de controle do município, a variável Micro controla os efeitos fixos de cada microrregião geográfica, a variável $T$ controla os efeitos temporais comuns a todas as localidades, e a variável $\mu$ traz o termo de erro. Já o primeiro estágio estima o efeito da variável $F$ por meio de instrumentos $Z$ conforme descrito na função (2):

$$
F_{i t}=\propto+\beta Z_{i t}+\varphi X_{i t}+\text { Micro }_{m}+T_{t}+v_{i t}
$$

na qual as variáveis instrumentais $Z$ devem ser diferentes das demais variáveis de controle em $X$. $\bigcirc$ termo de erro do primeiro estágio é representado por $\vartheta$. Diversos autores utilizam-se dessa abordagem para estimar o efeito da fiscalização sobre o mercado de trabalho. Além de Almeida e Carneiro (2012), McKenzie e Sakho (2010), a partir de um banco de da- 
dos detalhado sobre a fiscalização de firmas na Bolívia, sugerem utilizar a distância da firma para o centro da localidade e a distância da firma para a agência local de fiscalização como forma de identificação de probabilidade da firma ser auditada.

De fato, a Figura 2 sugere que, considerando o número de estabelecimentos fiscalizados em relação ao total de firmas, a fiscalização parece negativamente associada à distância (quanto mais distante for o município da capital estadual, menor o número de estabelecimentos fiscalizados) e também está negativamente associada à densidade de firmas por $\mathrm{km}^{2}$ (quanto maior o número de firmas por $\mathrm{km}^{2}$, menor o número de estabelecimentos fiscalizados), sendo que esta última correlação é mais forte. Por outro lado, o número de estabelecimentos fiscalizados por $\mathrm{km}^{2}$ está positivamente correlacionado com a distribuição das firmas pela área do município. Esse último dado reforça a ideia de que o modo de operação da fiscalização está associado a outros fatores, além da distância das agências e gerências de fiscalização.

Figura 2 Relação entre inspeções, densidade das firmas e distância
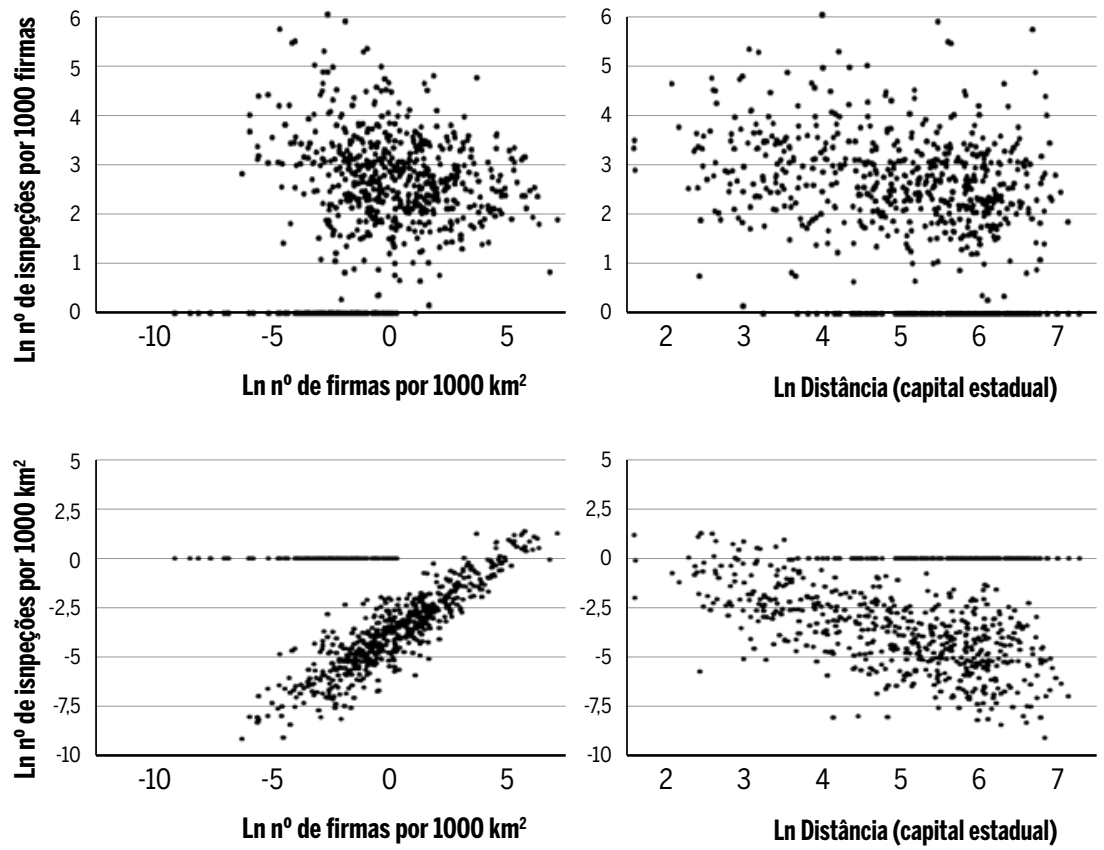
Conforme discutido na seção 2, Almeida e Carneiro (2012) fazem uso de uma estratégia de identificação similar. ${ }^{12}$ Com base nesse referencial e com base na discussão da seção 3 , aqui serão utilizados como instrumentos para o efeito de fiscalização a densidade do total de fiscais do trabalho por Estado e o logaritmo da densidade de firmas no município divididos pela distância em 1000 quilômetros da capital estadual. Assim, além da questão da distância, é considerada a distribuição dos fiscais e firmas por localidade. A ideia é explorar os aspectos associados à produtividade da fiscalização que tenderia a se concentrar em regiões mais densas. Conforme é possível verificar nos dados descritivos da Tabela 1, os fiscais por Estado (em maior número) são aqueles associados às Superintendências do MTE dos Estados. Já o número de fiscais por microrregião é bem menor e consolida o número de fiscais alocados nas Agências e Gerências das microrregiões conforme discutido na seção 3. Na seção 5 (Resultados) é discutida de maneira mais ampla a validade desses instrumentos.

\section{Resultados}

Com base na discussão metodológica da Seção 4, esta seção traz os resultados de regressões em mínimos quadrados ordinários (MOO) e variáveis instrumentais (IV). A Tabela 2 traz nas suas três primeiras colunas regressões nas quais a variável dependente é o logaritmo do número de estabelecimentos fiscalizados por 1000 firmas no município. Já as três últimas colunas trazem regressões considerando como variável dependente o número de firmas fiscalizadas por $1000 \mathrm{~km}^{2}$. A ideia aqui é explorar o aspecto geográfico do modo de operação da fiscalização do trabalho no Brasil, onde a fiscalização segue fatores como distância e densidade econômica (vide discussão na seção 3.1).

As regressões nas colunas (III) e (VI) consideram apenas os municípios que foram fiscalizados em todos os quatro anos da amostra, no caso 535 localidades. Já os demais resultados consideram todos os municípios da amostra que dispõem de informações sobre todas as variáveis utilizadas, em um total de 786 localidades, de modo que compõem um painel balan-

12 Uma diferença importante desta pesquisa em relação a Almeida e Carneiro (2012) é que os autores usam dados longitudinais, enquanto aqui, além de dados temporais para um período de quatro anos, são controlados os efeitos fixos para microrregiões do país. 
ceado. Deve-se ressaltar que todas as regressões controlam efeitos fixos das microrregiões, efeitos temporais e se referem ao período de 1996 à 1999, conforme descrito na função (1) na Seção 4. As regressões reportadas nas colunas (II), (III), (V) e (VI) se utilizam de variáveis instrumentais para abordar as variáveis de interesse referentes à fiscalização.

As estimativas em todas as regressões de variáveis instrumentais sugerem que o efeito de fiscalização é negativo e significante. $O$ coeficiente estimado para a regressão da Coluna (II), por exemplo, sugere que $1 \%$ de aumento em 1000 estabelecimentos fiscalizados reduz a informalidade em 0,107\% na localidade. Quando a variável considerada para efeito de fiscalização traz o logaritmo do número de estabelecimentos fiscalizados por $\mathrm{km}^{2}$, observa-se que as estimativas seguem a mesma tendência apresentada quando a variável de interesse é o número de estabelecimentos por total de firmas. As principais diferenças são que os coeficientes estimados apresentam uma magnitude menor e o nível de significância é maior. De acordo com os resultados apresentados na coluna $(\mathrm{V})$, para $1 \%$ de aumento de estabelecimentos fiscalizados por $1000 \mathrm{~km}^{2}$, estima-se um decréscimo de cerca de $0,043 \%$ na parcela de informais no município. Já os resultados para as regressões em $\mathrm{MQO}$ para essas variáveis, mesmo sendo significantes, são próximos a zero. De fato, no caso da variável de densidade da fiscalização, o coeficiente estimado é positivo, o que sugeriria que a fiscalização aumentaria a informalidade. Esses resultados (coluna I e IV) reforçam a ideia de que as estimativas com $\mathrm{MQO}$ são viesadas e, nesse caso, subestimam o verdadeiro efeito da fiscalização sobre a informalidade.

Em relação às demais variáveis explicativas, em quase todas as regressões, os coeficientes para a proporção de idosos na população e escolaridade são estimados como bastante significantes para compreender a proporção de trabalhadores informais. Enquanto o aumento da escolaridade reduz a proporção de trabalhadores informais, o aumento de idosos na população atua na direção oposta. Possivelmente, esse último resultado pode estar associado ao fato de que a parcela de idosos apresenta um grande contingente de aposentados e pensionistas que podem estar complementando a renda da aposentadoria no mercado informal. De maneira interessante, as estimativas sugerem que o aumento da renda familiar total é mais significante para compreender a redução da informalidade do que a renda familiar per capita. Ou seja, o aumento da renda familiar parece funcionar como uma barreira para o ingresso dos membros da família no mercado informal de trabalho. 
Tabela 2 Estimativas para o efeito de fiscalização no mercado de trabalho sobre a informalidade

\begin{tabular}{|c|c|c|c|c|c|c|}
\hline $\begin{array}{l}\text { Variável dependente: } \\
\text { Informalidade }\end{array}$ & $\begin{array}{r}\text { MQO } \\
\text { (I) }\end{array}$ & $\begin{array}{r}\text { Var. Instr. } \\
\text { (II) }\end{array}$ & $\begin{array}{r}\text { Var. Instr. } \\
\text { (III) }\end{array}$ & $\begin{array}{r}\text { MQO } \\
\text { (IV) }\end{array}$ & $\begin{array}{r}\text { Var. Instr. } \\
\text { (V) }\end{array}$ & $\begin{array}{r}\text { Var. Instr. } \\
\text { (VI) }\end{array}$ \\
\hline Ln $n^{0}$ inspeções por 1000 firmas & $\begin{array}{r}* * *-0,008 \\
(-5,090)\end{array}$ & $\begin{array}{r}* * *-0,107 \\
(-3,360)\end{array}$ & $\begin{array}{r}* * *-0,104 \\
(-2,645)\end{array}$ & & & \\
\hline $\operatorname{Ln} n^{0}$ inspeções por $1000 \mathrm{Km}^{2}$ & & & & $\begin{array}{r}* * * 0,001 \\
(0,710)\end{array}$ & $\begin{array}{r}* * *-0,043 \\
(-4,624)\end{array}$ & $\begin{array}{r}* * * 0,023 \\
(-4,898)\end{array}$ \\
\hline$\%$ Brancos & $\begin{array}{r}0,017 \\
(1,100)\end{array}$ & $\begin{array}{r}0,029 \\
(1,203)\end{array}$ & $\begin{array}{r}0,002 \\
(0,097)\end{array}$ & $\begin{array}{r}0,017 \\
(1,060)\end{array}$ & $\begin{array}{r}0,020 \\
(0,972)\end{array}$ & $\begin{array}{r}0,004 \\
(0,209)\end{array}$ \\
\hline$\%$ Homens & $\begin{array}{r}0,055 \\
(0,820)\end{array}$ & $\begin{array}{r}0,008 \\
(0,088)\end{array}$ & $\begin{array}{r}0,029 \\
(0,279)\end{array}$ & $\begin{array}{r}0,058 \\
(0,860)\end{array}$ & $\begin{array}{l}{ }^{*} 0,135 \\
(1,762)\end{array}$ & $\begin{array}{r}0,052 \\
(0,595)\end{array}$ \\
\hline$\%$ Idosos & $\begin{array}{r}* * * 0,526 \\
(5,900)\end{array}$ & $\begin{array}{r}-0,004 \\
(-0,021)\end{array}$ & $\begin{array}{r}* *_{0}^{*} 0,378 \\
(2,211)\end{array}$ & $\begin{array}{r}* * * 0,565 \\
(6,330)\end{array}$ & $\begin{array}{r}* * * 0,504 \\
(4,473)\end{array}$ & $\begin{array}{r}* * * 0,527 \\
(4,717)\end{array}$ \\
\hline$\%$ Crianças & $\begin{array}{r}0,007 \\
(0,130)\end{array}$ & $\begin{array}{r}-0,110 \\
(-1,340)\end{array}$ & $\begin{array}{r}-0,066 \\
(-0,804)\end{array}$ & $\begin{array}{r}0,014 \\
(0,270)\end{array}$ & $\begin{array}{r}0,050 \\
(0,721)\end{array}$ & $\begin{array}{r}-0,027 \\
(-0,418)\end{array}$ \\
\hline Anos de Estudo & $\begin{array}{r}* * * 0,037 \\
(-12,500)\end{array}$ & $\begin{array}{r}* * *-0,039 \\
(-8,794)\end{array}$ & $\begin{array}{r}* * * 0,031 \\
(-7,021)\end{array}$ & $\begin{array}{r}* * *-0,036 \\
(-12,470)\end{array}$ & $\begin{array}{r}* * *-0,025 \\
(-5,333)\end{array}$ & $\begin{array}{r}* * *-0,025 \\
(-6,643)\end{array}$ \\
\hline Ln Renda Familiar per capita & $\begin{array}{r}-0,003 \\
(-0,200)\end{array}$ & $\begin{array}{r}-0,006 \\
(-0,240)\end{array}$ & $\begin{array}{r}0,030 \\
(1,064)\end{array}$ & $\begin{array}{r}-0,004 \\
(-0,220)\end{array}$ & $\begin{array}{r}0,002 \\
(0,073)\end{array}$ & $\begin{array}{r}0,034 \\
(1,524)\end{array}$ \\
\hline Ln Renda Familiar total & $\begin{array}{r}-0,017 \\
(-1,010)\end{array}$ & $\begin{array}{r}-0,004 \\
(-0,148)\end{array}$ & $\begin{array}{l}*-0,058 \\
(-1,959)\end{array}$ & $\begin{array}{r}-0,017 \\
(-1,050)\end{array}$ & $\begin{array}{r}*-0,042 \\
(-1,789)\end{array}$ & $\begin{array}{r}* *-0,054 \\
(-2,404)\end{array}$ \\
\hline Total Trabalhadores UF & $\begin{array}{r}-0,000 \\
(-0,470)\end{array}$ & $\begin{array}{r}0,000 \\
(0,443)\end{array}$ & $\begin{array}{r}-0,000 \\
(-0,562)\end{array}$ & $\begin{array}{r}-0,000 \\
(-0,530)\end{array}$ & $\begin{array}{r}-0,000 \\
(-1,186)\end{array}$ & $\begin{array}{r}-0,000 \\
(-0,037)\end{array}$ \\
\hline Total Firmas UF & $\begin{array}{r}-0,000 \\
(-0,420)\end{array}$ & $\begin{array}{r}0,000 \\
(1,552)\end{array}$ & $\begin{array}{r}0,000 \\
(0,346)\end{array}$ & $\begin{array}{r}-0,000 \\
(-0,660)\end{array}$ & $\begin{array}{r}0,000 \\
(0,359)\end{array}$ & $\begin{array}{r}-0,000 \\
(-1,090)\end{array}$ \\
\hline Ln população & $\begin{array}{r}* * *-0,014 \\
(-6,040)\end{array}$ & $\begin{array}{r}-0,003 \\
(-0,541)\end{array}$ & $\begin{array}{r}* * *-0,031 \\
(-3,935)\end{array}$ & $\begin{array}{r}* * *-0,015 \\
(-6,260)\end{array}$ & $\begin{array}{r}* * *-0,029 \\
(-6,860)\end{array}$ & $\begin{array}{r}-0,004 \\
(-1,349)\end{array}$ \\
\hline $\begin{array}{l}\text { Ln tamanho da firma } \\
\text { (func./firma) }\end{array}$ & $\begin{array}{r}* * *-0,019 \\
(-4,240)\end{array}$ & $\begin{array}{r}-0,009 \\
(-1,094)\end{array}$ & $\begin{array}{r}-0,008 \\
(-0,415)\end{array}$ & $\begin{array}{r}* * *-0,020 \\
(-4,400)\end{array}$ & $\begin{array}{r}-0,008 \\
(-1,136)\end{array}$ & $\begin{array}{r}* * *-0,037 \\
(-4,158)\end{array}$ \\
\hline Densidade populacional & $\begin{array}{r}0,000 \\
(0,750)\end{array}$ & $\begin{array}{r}* *-0,000 \\
(-2,541)\end{array}$ & $\begin{array}{r}-0,000 \\
(-1,064)\end{array}$ & $\begin{array}{r}* * * 0,000 \\
(0,880)\end{array}$ & $\begin{array}{r}* * * 0,000 \\
(3,805)\end{array}$ & $\begin{array}{r}{ }^{*} 0,000 \\
(1,921)\end{array}$ \\
\hline Teste $\mathrm{F}\left(1^{0}\right.$ estágio) & & 19,621 & 15,37 & & 9,31 & 19,93 \\
\hline Teste J Sargan - (valor $p$ ) & & 0,1243 & 0,1131 & & 0,7481 & 0,82 \\
\hline Número de observações & 3.144 & 3.144 & 2.140 & 3.144 & 3.144 & 2.140 \\
\hline
\end{tabular}

Obs: Em parênteses estão t valores robustos quanto a heterocedasticidade.

* Significante em 10\%; ** Significante em 5\%; *** Significante em 1\%.

Todas regressões incluem efeitos temporais. Regressões em IV incluem efeitos fixos para microregiões geográficas. 
Ainda de acordo com os resultados, a proporção de informais é menor quanto maior a população, e quanto maior o tamanho (de acordo com o número de trabalhadores) das firmas, porém, o nível de significância dos coeficientes dessas variáveis é pouco estável entre as regressões, alternando coeficientes significantes com coeficientes não significantes. A informalidade também parece estar positivamente associada à maior proporção de homens e negativamente associada à maior parcela de crianças na população, mas esses coeficientes não são significativos. Também os coeficientes estimados para as variáveis referentes à proporção de brancos na população e número de trabalhadores e firmas nos Estados são insignificantes e parecem ter pouco impacto sobre a informalidade nos municípios, com coeficientes estimados insignificantes e próximos de zero.

Adicionalmente, é importante discutir se as estimativas com variáveis instrumentais realmente produzem coeficientes consistentes. Na Tabela 2, os resultados do teste F sugerem que os instrumentos escolhidos (densidade do total de firmas do município divididos por distância da capital estadual, densidade do número de fiscais por Estado) estão correlacionados com as inspeções trabalhistas de maneira significante. ${ }^{13}$ Além disso, os $p$ valores do teste $J$ de Hansen de sobre identificação dos instrumentos sugerem que os instrumentos utilizados são válidos e não estão correlacionados com o termo de erro. $\mathrm{O}$ fato das estimativas na amostra total $\mathrm{e}$ na subamostra de municípios fiscalizados todos os anos serem próximos também reforça a consistência dos resultados.

Por fim, apesar de não serem diretamente comparáveis, esses resultados são próximos aos encontrados por Almeida e Carneiro (2012). Usando dados longitudinais do Censo de 2000, os autores também encontram um efeito relevante da fiscalização sobre a mobilidade dos trabalhadores informais e autônomos para o setor formal no mercado de trabalho no Brasil.

\section{Conclusão}

A informalidade se constitui em um aspecto importante do mercado de trabalho no Brasil. Devido aos impactos da informalidade na precarização

13 Os resultados do $1^{\circ}$ estágio estão no Apêndice. De acordo com Stock e Yogo (2002), valores acima de 10 na estatística $F$ reforçam a significância das variáveis selecionadas como instrumentos. 
das relações trabalhistas e na queda de arrecadação do governo nas contribuições da área, o governo vem investindo em ações de fiscalização nas firmas. Desse modo, é importante compreender os efeitos da fiscalização no mercado de trabalho.

Este estudo investiga os efeitos da fiscalização sobre a parcela de trabalhadores informais nos municípios brasileiros. Para realizar essa investigação, a pesquisa se utiliza de dados do MTE sobre o número de estabelecimentos fiscalizados e números de fiscais do trabalho para o período de 1996 à 1999. A amostra da pesquisa se constitui de 786 municípios cujas informações estão disponíveis para esse período na PNAD contínua. Os resultados apontam que a fiscalização tem um impacto negativo e significante na parcela de trabalhadores informais nos municípios investigados.

Adicionalmente, é analisado o modo de operação da fiscalização trabalhista no país que sofreu diversas alterações na década de 90. Apesar dessas alterações, uma das principais características das ações de fiscalização no Brasil, e também em outros países, é que a decisão de fiscalização não é aleatória, mas depende de características observadas e não observadas das localidades. Por conta dessas características, para obter uma estimativa consistente dos efeitos da fiscalização é empregada uma metodologia de variáveis instrumentais.

Uma novidade aqui apresentada em relação a trabalhos anteriores, em especial a Almeida e Carneiro (2012), é utilizar dados com mais de uma observação temporal (estrutura de painel de dados) e investigar os aspectos geográficos da fiscalização além da questão da distância. De acordo com a estratégia de identificação utilizada nesta pesquisa, além da distância das localidades para o centro da fiscalização no Estado, também importa a concentração geográfica das firmas nas localidades (densidade) e o agrupamento de microrregiões geográficas pelo país. Considerando-se o aspecto geográfico do modo de operação da fiscalização, pesquisa nessa área se beneficiaria de investigações adicionais sobre os efeitos de fiscalização em localidades vizinhas sobre a informalidade no mercado de trabalho do próprio município.

\section{Referências}

AHN, N.; DE LA RICA, S. The underground economy in Spain: an alternative to unemploy- 
ment? Applied Economics, 29, 733-743, 1997.

ALMEIDA, R.; CARNEIRO, P. Enforcement of Labor Regulation and Informality. American Economic Journal: Applied Economics, 4(3), p. 64-89, 2012.

ANDRADE, G. H.; BRUHN, M.; MCKENZIE, D. A Helping Hand or the Long Arm of the Law? Experimental Evidence on What Governments Can Do to Formalize Firms. World Bank Economic Review, 30 (1), p. 24-54, 2014.

BERG, J. Laws or Luck? Understanding Rising Labor Formality in Brazil in the 2000s. Working paper $n^{\circ} 5$, ILO Brazil, 2010.

CORSEUIL, C. H. L.; ALMEIDA, R.; CARNEIRO, P. Inspeção do Trabalho e Evolução do Emprego Formal no Brasil. Texto para Discussão 1688, IPEA. Brasília, 2012.

FOGUEL, M.; BARROS, R. The effects of conditional cash transfer programmes on adult labour supply: an empirical analysis using a timeseries-cross-section sample of Brazilian municipalities. Estudos Econômicos, São Paulo, v. 40, n. 2, p. 259-293, abril-junho 2010.

FUGAZZA, M.; JACQUES, J. F. Labor market institutions, taxation and the underground economy. Journal of Public Economics, v. 88, n. 1-2, p. 395-418, 2003.

MCKENZIE, D.; SAKHO, Y. S. Does it Pay Firms to Register for Taxes? The Impact of Formality on Firm Profitability. Journal of Development Economics, 91 (1), p. 15-24, 2010.

PERRY, G. E. et al. Informality: Exit and Exclusion. World Bank Latin American and Caribbean Studies Annual Flagship Report. Washington, DC, May 2007.

PIRES, R. Promoting Sustainable Compliance: Styles of Labour Inspection and Compliance Outcomes in Brazil. International Labour Review, v. 147, n. 2-3, p. 199-229, 2008.

STOCK, J. H.; YOGO, M. Testing for weak instruments in linear IV regression. Technical working paper 284. NBER, 2002.

ULYSSEA, G.; PAES DE BARROS, R. On the Empirical Content of the Formal-Informal Labor Market Segmentation Hypothesis. Brazilian Review of Econometrics, 30(2), p. 289-310, 2010.

\section{Sobre os autores}

Enlinson Mattos - enlinson.mattos@fg.br

Fundação Getulio Vargas, Escola de Economia de São Paulo, São Paulo, SP.

Ricardo Politi-rbpoliti@hotmail.com

Universidade Federal do ABC, São Bernardo do Campo, SP.

Gabriela Fuschini -gabrielafuschini@gmail.com

Tendencias Consultoria, São Paulo, SP.

\section{Sobre $\mathrm{o}$ artigo}

Recebido em 30 de junho de 2015. Aprovado em 19 de setembro de 2016. 


\section{APÊNDICE}

Tabela A1 Regressões $1^{\circ}$ estágio

\begin{tabular}{|c|c|c|}
\hline Variável dependente: & $\begin{array}{l}\text { Ln } n^{0} \text { inspeções } \\
\text { por } 1000 \text { firmas }\end{array}$ & $\begin{array}{r}\text { Ln } n^{0} \text { inspeções } \\
\text { por } 1000 \text { km2 }\end{array}$ \\
\hline Densidade firma/ distância & $\begin{array}{r}-0,068^{* * *} \\
(-5,620)\end{array}$ & $\begin{array}{r}0,368^{* * *} \\
(5,950)\end{array}$ \\
\hline Densidade Fiscais Estado & $\begin{array}{r}1.330 .508^{* * *} \\
(5,910)\end{array}$ & $\begin{array}{r}0,178 \\
(0,830)\end{array}$ \\
\hline$\%$ Brancos & $\begin{array}{r}0,099 \\
(0,520)\end{array}$ & $\begin{array}{r}0,077 \\
(0,230)\end{array}$ \\
\hline$\%$ Homens & $\begin{array}{r}-0,422 \\
(-0,680)\end{array}$ & $\begin{array}{r}1.714 .989 \\
(1,440)\end{array}$ \\
\hline$\%$ Idosos & $\begin{array}{r}-462.302^{* * *} \\
(-4,470)\end{array}$ & $\begin{array}{r}1.281 .973 \\
(0,700)\end{array}$ \\
\hline$\%$ Crianças & $\begin{array}{r}-1.079 .697,000^{*} \\
(-1,700)\end{array}$ & $\begin{array}{r}1.137 .015 \\
(0,990)\end{array}$ \\
\hline Anos de Estudo & $\begin{array}{r}-0,030 \\
(-0,900)\end{array}$ & $\begin{array}{l}0,158^{* *} \\
(2,210)\end{array}$ \\
\hline Ln Renda Familiar per capita & $\begin{array}{r}0,019 \\
(0,090)\end{array}$ & $\begin{array}{r}0,027 \\
(0,060)\end{array}$ \\
\hline Ln Renda Familiar total & $\begin{array}{r}0,120 \\
(0,550)\end{array}$ & $\begin{array}{r}-0,396 \\
(-0,940)\end{array}$ \\
\hline Total Trabalhadores UF & $\begin{array}{r}0,000 \\
(0,930)\end{array}$ & $\begin{array}{l}-0,000^{*} \\
(-1,840)\end{array}$ \\
\hline Total Firmas UF & $\begin{array}{r}0,000^{* * * *} \\
(2,630)\end{array}$ & $\begin{array}{r}0,000 \\
(0,960)\end{array}$ \\
\hline Ln população & $\begin{array}{r}0,155^{* * *} \\
(4,850)\end{array}$ & $\begin{array}{r}-0,490 * * * \\
(-8,080)\end{array}$ \\
\hline $\begin{array}{l}\text { Ln tamanho da firma } \\
\text { (func./firma) }\end{array}$ & $\begin{array}{r}0,107 \\
(1,570) \\
\end{array}$ & $\begin{array}{r}0,344^{* * *} \\
(3,130)\end{array}$ \\
\hline Densidade populacional & $\begin{array}{r}-0,000^{* *} \\
(-1,970)\end{array}$ & $\begin{array}{r}0,000^{* * *} \\
(9,150)\end{array}$ \\
\hline
\end{tabular}

Obs: Em parênteses estão t valores robustos quanto a heterocedasticidade.

* Significante em 10\%; ** Significante em 5\%; *** Significante em 1\%.

Todas regressões incluem efeitos temporais. Regressões em IV incluem efeitos fixos para microregiões geográficas. 